\title{
The impact of international benchmarking on the price of immunosuppressive medicines for transplant recipients in South Africa
}

\author{
K-L Cassar, ${ }^{1}$ BPharm; F Suleman, ${ }^{1,2}$ BPharm, MPharm, PhD \\ ${ }^{1}$ Discipline of Pharmaceutical Sciences, School of Health Sciences, University of KwaZulu-Natal, Durban, South Africa \\ ${ }^{2}$ Faculty of Science, Utrecht University, The Netherlands
}

Corresponding author: K-L Cassar (kerrylouisecassar@gmail.com)

\begin{abstract}
Background. External reference pricing (ERP) is an internationally applied pricing policy to regulate the price of medicines. In 2005, the South African (SA) Minister of Health published a Government Gazette of regulations relating to a transparent pricing system for medicines and scheduled substances, stating that the Minister must publish a methodology for conforming to international benchmarks. In May 2014, the most recent proposed benchmark methodology was published, detailing that international benchmarking of medicines (IBM) requires that the lowest price in a selected basket of countries (Australia, Canada, New Zealand, Spain and SA) be used as the ultimate price for the purposes of benchmarking of originator products.

Objectives. To provide a broad observational basis for the use of IBM and the proposed countries as a pricing tool; the feasibility of using BRICS countries (Brazil, Russia, India, China and SA) as comparator countries; and a small sample comparison of local state tender pricing in relation to the IBM proposed basket of comparator country pricing. Immunosuppressant medicines for organ transplant patients were used for this comparison, as they are relatively expensive and there is reluctance to implement pricing and reimbursement policy options to contain their costs.

Methods. Ex-manufacturer medicine pricing information for 2016, 2017 and 2018 was sourced for immunosuppressive medicines for SA (public and private sectors), Australia, New Zealand, Canada, Spain, Brazil and Russia. Unit prices were compared for products with the same international non-proprietary name (INN), strength, formulation and manufacturer. In most cases the products were matched on product name, bearing translation nuances in mind.

Results. Across all 3 years, in the majority of products, ERP using the proposed basket of comparator countries Australia, New Zealand, Canada and Spain lowered the local private sector ex-manufacturer price of medicine. Similarly, for the majority of products comparing local pricing with that of available BRICS country pricing data, the comparison lowered the price. For $92 \%$ of products where a comparison could be made, the SA state tender price was the lowest available price.

Conclusions. Conducting an ERP analysis consumes time and resources. However, it may prove to reduce a current or proposed medicine price and may be considered as one of a range of medicine pricing policies employed by a country. It should not be used in isolation from other medicine pricing and reimbursement policies.
\end{abstract}

S Afr Med J 2019;109(11):865-871. https://doi.org/10.7196/SAMJ.2019.v109i11.13944

According to the Council for Medical Schemes Annual Report for $2017 / 2018$, $^{[1]} 16.08 \%$ of total benefits paid by medical schemes in 2017 were for medicines. This high proportion of spend on medicines in the population with medical insurance in South Africa (SA) highlights the importance of medicine price regulation and the need for robust tools and policies to contain costs in order to manage resources. In 2005, the SA Minister of Health published a Government Gazette of regulations relating to a transparent pricing system for medicines and scheduled substances. ${ }^{[2]}$ The Single Exit Price (SEP) legislation detailed in this Gazette aimed to regulate medicine pricing and remove the practice of discounts and rebates where benefits were not reaped by consumers. ${ }^{[3]}$ When initially implemented, the SEP had a significant impact on the price of medicines and medicine expenditure, but over time a rebound in pricing was observed. ${ }^{[3]}$ However, the SEP implementation was only intended to be the first phase of addressing medicine price concerns at the ex-manufacturer level. ${ }^{[3]}$ To address the second phase, it was noted in the 2005 Gazette ${ }^{[2]}$ that the Minister must publish in the Gazette a methodology for conforming to international benchmarks. In December 2006, the initial methodology for international benchmarking of the prices of medicines and scheduled substances in SA was published for comment. ${ }^{[4]}$ In December 2010, a subsequent detailed proposed methodology addressing commentary was published for further comment. ${ }^{[3]}$ In May 2014, the most recent proposed methodology for regulations relating to a transparent pricing system for medicines and scheduled substances (benchmark methodology) was published. ${ }^{[5]}$

'The aim of international benchmarking, together with other regulatory interventions, is to:

Protect the South African health system from paying distorted prices for medicines through the elimination of price distortions and price distorting behaviour. ${ }^{\text {[3] }}$

The Pricing Committee and the National Department of Health $(\mathrm{NDoH})$ wish to establish a programme in SA that involves negotiating drug prices that relate to the drugs' therapeutic performance but also takes socioeconomic factors into account. ${ }^{[5]}$ The proposed methodology for international benchmarking of medicines (IBM), referred to internationally as external reference pricing (ERP), 
requires that the lowest price in a selected basket of countries be used as the ultimate price for the purposes of benchmarking. The selected basket of countries includes Australia, Canada, New Zealand, Spain and SA. ${ }^{[5]}$ The NDoH may review the basket every 2 years and a possible complementary list of benchmark countries may be published online. ${ }^{[5]}$ The proposed methodology includes two protections against the potential for inappropriate reductions of prevailing prices at implementation. ${ }^{[5]}$ These are an exemption application process and a phased approach that will delay the implementation of the ultimate benchmark by 2 years. The first phase of the phased approach will set the benchmark at the average of prices in the proposed country basket, and the second phase will implement the ultimate benchmark of the lowest price in the proposed country basket. ${ }^{\left[{ }^{5}\right]}$ This most recent proposed methodology was published in 2014, and no subsequent proposed changes or final benchmark methodologies have been published. Applicants are not prevented from complying with the proposed methodology in the interim. ${ }^{[5]}$

Evidence regarding the impact of different pricing policies on medicine prices is scarce, especially in low-income countries. This issue is twofold, as it refers not only to a lack of evidence but also a potential lack of successful pricing policy implementation. ${ }^{[6,7]}$ Literature assessing whether medicine prices would be lowered on implementation of this IBM/ERP policy is lacking.

Furthermore, the current proposed basket of countries was chosen on the basis of prespecified criteria selecting countries with effective systems for pricing and regulating medicines. ${ }^{[3]}$ However, their health system structure and socioeconomic background may be significantly different from that of SA. A major factor that contributed to the resultant proposed list of benchmark countries was accessibility to pricing data. ${ }^{[5]}$ As emerging economies, BRICS countries (Brazil, Russia, India, China and SA) may appear to be more suitable economic comparators, but a thorough economic analysis would be required to ascertain economic comparability if that was a primary reason for inclusion. The aim of the co-operation among the BRICS countries is non-competitive, sustainable, equitable and mutually beneficial development, and at the BRICS meeting of health ministers in July 2018, access to medicines was one of the five key topics discussed. ${ }^{[8]}$ This collaboration may therefore facilitate access to transparent pricing information, including unpublished confidential discounts on listed prices, among BRICS medicine agencies.

The SA state sector is currently not subject to the SEP legislation and makes use of tender processes to procure medicines by means of volume-based purchasing. ${ }^{[9]}$ A secondary analysis aimed to provide insight into whether state tender prices remain consistently low when compared with private sector SA medicine prices and the proposed basket of comparator countries.

\section{Objectives}

The purpose of this observational analysis was to determine whether implementation of the proposed methodology for IBM would have a positive (cost-saving) impact on the prices of immunosuppressive medicines for transplant patients. The primary comparison aimed to assess whether the application of IBM with the proposed basket of comparator countries would lower the price of medicines locally. The secondary analysis aimed to assess whether using BRICS countries as a benchmark would lower the local price of medicine. Furthermore, a comparison of SA government sector tender prices with the five proposed comparator countries (SA private sector, Australia, Canada, New Zealand, Spain) aimed to assess whether state tender prices are the lowest.
Internal reference pricing as a cost-minimisation tool may not be considered a feasible instrument to implement for this particular group of medicines, but international benchmarking may provide an alternative mechanism to lower the cost of medicines in this group in a manner that does not directly involve the person using the medicine.

Overall, the objectives of this study were to provide a broad observational basis for the use of IBM and the proposed countries as a pricing tool, the feasibility of using BRICS countries as comparator countries, and a small sample comparison of local state tender pricing in relation to the pricing from the proposed basket of comparator countries.

\section{Methods}

Ethical clearance was obtained from the University of KwaZulu-Natal (ref. no. HSS/0154/013).

\section{Selection of medicines}

Immunosuppressants used to prevent graft rejection were selected from Anatomical Therapeutic Classification (ATC) class L04A Immunosuppressants. As this list is exhaustive and not exclusive to medicines used to prevent graft rejection, local and international registration status was determined to isolate the international nonproprietary name (INN) products used in this setting. Products registered locally or by the US Food and Drug Administration or the European Medicines Agency were included in the list for the sourcing of pricing information.

Equine gamma globulin (Atgam) is classified under the ATC group L04AA and is registered for acute use in renal transplant rejection. This acute use differs from the long-term prophylactic nature of the other immunosuppressants included for comparison from L04A; however, as the list of products for comparison was already small, further exclusion due to duration and setting of use was not enforced.

\section{Time frame of medicine pricing information}

An attempt to obtain pricing information for 2016, 2017 and 2018 for all comparator countries was made. This was successful with the exception of Spain, despite repeated attempts to obtain historical pricing information (2016 and 2017) from the Spanish authorities and academics in that country.

\section{Data sources}

In accordance with the specifications of the Gazette methodology, the ex-manufacturer prices of the comparator countries were sourced. Publicly available online sources of ex-manufacturer pricing were obtained for Australia, Canada, New Zealand, Spain, SA (private sector ex-manufacturer and state tender), Brazil and Russia. Prices for Australia were obtained online from the Pharmaceutical Benefit Scheme, ${ }^{[10]}$ for Canada from the Alberta Drug Benefit List, ${ }^{[11]}$ for New Zealand from the PHARMAC online schedule, ${ }^{[12]}$ and from the Spanish Ministry of Health, Consumer Affairs and Social Welfare. ${ }^{[13]}$

It was assumed that the ex-manufacturer or ex-factory price should be devoid of any mark-ups and inclusion of VAT; however, where the published prices were not explicitly ex-factory prices, details have been provided as to how the ex-factory prices were calculated or confirmed.

The National Pharmaceutical Pricing Authority of the Government of India provides an online public pricing resource of scheduled formulations, ${ }^{[14]}$ but as the price is regulated at the maximum retail price and that is the published price, no public resource of regulated 
ex-manufacturer pricing was found. A resource of state tender pricing was also found, but would not be an appropriate comparator for this benchmarking analysis. ${ }^{[15]}$

Although reform of the price setting of medicine in China is underway, ${ }^{[16]}$ no formal publicly available resource of medicine pricing was found. The China Drug and Food Administration drug database does not include pricing. ${ }^{[17]}$

An online appendix with detailed information on how ex-factory prices were obtained from the online resources is available (http:// samj.org.za/public/sup/online_appendix.docx).

\section{Pricing}

In line with the Gazette methodology, medicine prices were converted to South African rands (ZAR) using the average currency exchange rate for the particular currency for the past 12 months. Historical exchange rate data were obtained from the South African Reserve Bank website. ${ }^{[18]}$ The time ranges of historical data exported were for 1 January 2016 - 31 December 2016, 1 January 2017 - 31 December 2017, and 1 June 2017 - 31 May 2018. The ranges were exported in Excel 2013 (Microsoft, USA) and an average conversion rate for the time range was calculated in Excel.

\section{Sorting process}

Data lines were matched on the basis of the same INN, strength, formulation and manufacturer. In most cases the products were matched on product name, bearing in mind translation nuances. Where products were matched on all the listed criteria but the trade name varied (e.g Mycocept and Mycophenolate Sandoz), they were still grouped together. Different pack sizes were included in the same group and in all cases pricing was compared on unit price level. Generic products were not excluded; however, only products where SA private sector pricing was available were assessed.

The Government Gazette 37625 Regulations relating to a transparent pricing system for medicines and scheduled substances (benchmark methodology) published in May 2014 $4^{[5]}$ state that the IBM methodology will apply to all originator medicines for which there are fewer than two generic competitors. On completion of this phase of implementation, it is the intention of the Minister of Health to address the methodology for originator medicines with two or more generic competitors and generic medicines. For the purposes of this analysis, products were not included or excluded on this basis.

\section{Assessment of products}

Products were analysed per year using six key questions:

A. Would benchmarking against the four countries listed in the proposed basket of comparator countries (Australia, New Zealand, Canada and Spain) decrease the SA medicine price? For how many products did benchmarking against these countries lower the price?

B. Is the full benchmarking basket available (Australia, New Zealand, Canada and Spain)?

C. Which benchmarking country has the lowest price (by frequency)?

D. Would benchmarking against the remaining BRICS countries decrease the SA medicine price?

E. Which BRICS country has the lowest price (by frequency)?

F. Is the state tender pricing lower than all countries in the proposed basket of comparator countries, and for products where state tender prices are available, for how many products was the state tender price the lowest price compared with the proposed basket of comparator countries?

\section{Results}

Pricing information was sourced for products containing ciclosporin, mycophenolate mofetil, mycophenolic acid, sirolimus, tacrolimus, everolimus, azathioprine and equine gamma globulin.

Table 1 presents a summary of the results. Using pricing data from 2016, 2017 and 2018, a total of 78 IBM immunosuppressant products were analysed in accordance with the proposed ultimate IBM methodology stipulating that the lowest price in the proposed comparator countries (including SA) must become the benchmark price. Owing to a more limited number of appropriate product pricing matches, a smaller number of products, 66, were analysed using the same methodology but with BRICS countries as comparators. The application of the IBM methodology lowered the SA private sector ex-manufacturer price in $68 \%, 85 \%$ and $85 \%$ of products in 2016, 2017 and 2018, respectively. In only one product across all three years was the full benchmarking set of country data available, and for that product, Spain had the lowest price listed (Pfizer Rapamune sirolimus $1 \mathrm{mg}$ tablet). Australia consistently had the highest frequency of the lowest price; however, where New Zealand pricing was available it demonstrated the largest average percentage decrease of price by a benchmarking country consistently in 2016 (60\%), 2017 (53\%) and 2018 (56\%).

Looking at the BRICS countries, ex-manufacturer pricing data were obtained for Brazil and Russia. By comparison against these two countries, the SA private sector ex-manufacturer price was lowered in $81 \%, 90 \%$ and $81 \%$ of products where a comparator price was available in 2016, 2017 and 2018, respectively. In the majority of products in 2016, 2017 and 2018, Russia had the highest frequency of the lowest price.

Where an SA state tender price was available for a product, it was compared with the proposed basket of comparator countries where available, including the SA private sector ex-manufacturer price; 38 products were assessed for this comparison. In each year, in $92 \%$ of products where a comparison could be made, the SA state tender price was the lowest available price.

Table 2 presents a summary of the medicine products assessed for each comparison. In all 3 years the originator products that included only BRICS comparators were Novartis Simulect (basilixmab) $20 \mathrm{mg}$ vial and Astellas Prograf (tacrolimus) $5 \mathrm{mg} / \mathrm{mL} 1 \mathrm{~mL}$ injection.

\section{Discussion}

This observational analysis of immunosuppressant medicines showed that for the majority of products, ERP using the proposed basket of comparator countries Australia, New Zealand, Canada and Spain lowered the price of the medicine. Similarly, for the majority of products comparing local pricing with that of available BRICS country pricing data, the comparison lowered the local private sector ex-manufacturer price of medicine.

Historical information for Spanish medicine pricing was not available, so only pricing for 2018 was available for capturing and comparison. The 2018 comparison for Pfizer's Rapamune (sirolimus) $1 \mathrm{mg}$ tablets was the only case in which information was available for all five proposed comparator countries including Australia, New Zealand, Canada, Spain, and of course SA. Most products had pricing for SA and two other reference price countries. Most frequently, Australia had the lowest price in the proposed basket of comparator countries; however, where available, New Zealand pricing consistently demonstrated the largest average percentage decrease of price (average decrease of $56 \%$ in 20 products).

The proposed benchmarking methodology Gazette published in $2010^{[3]}$ provides thorough detail on the selection criteria applied to 


\section{Table 1. Summary of results ${ }^{\star}$}

\begin{tabular}{|c|c|c|c|c|}
\hline & & 2016 & 2017 & 2018 \\
\hline & IBM benchmarking products, $n$ & 25 & 27 & 26 \\
\hline \multirow[t]{2}{*}{ A } & Products where the proposed basket lowered price, $n$ & 17 & 23 & 22 \\
\hline & Products where the proposed basket lowered price, \% & 68 & 85 & 85 \\
\hline \multirow[t]{6}{*}{ B } & Full benchmarking country set, $n$ & 0 & 0 & 1 \\
\hline & Products with $3 / 4$ countries plus SA, $n$ & 7 & 7 & 9 \\
\hline & Products with $2 / 4$ countries plus $S A, n$ & 13 & 16 & 14 \\
\hline & Products with $1 / 4$ countries plus SA, $n$ & 5 & 4 & 2 \\
\hline & Products with no price change (SA lowest), $n$ & 8 & 4 & 4 \\
\hline & Products with no price change, $\%$ & 32 & 15 & 15 \\
\hline \multirow[t]{7}{*}{$\mathrm{C}$} & Lowest-priced country by frequency, $n$ & & & \\
\hline & Australia & 11 & 14 & 12 \\
\hline & New Zealand & 6 & 8 & 8 \\
\hline & SA & 7 & 4 & 4 \\
\hline & Canada & 1 & 1 & 1 \\
\hline & Spain & 0 & 0 & 1 \\
\hline & BRICS products, $n$ & 21 & 21 & 21 \\
\hline \multirow[t]{2}{*}{ D } & Price lowered by comparator countries, $n$ & 17 & 19 & 17 \\
\hline & Products where BRICS comparator lowered price, $\%$ & 81 & 90 & 81 \\
\hline \multirow[t]{4}{*}{$\mathrm{E}$} & Lowest-priced country frequency, $n$ & & & \\
\hline & Russia & 13 & 18 & 16 \\
\hline & Brazil & 4 & 1 & 2 \\
\hline & SA & 4 & 2 & 3 \\
\hline \multirow[t]{8}{*}{$\mathrm{F}$} & In products where state tender prices are available, $n$ products available & 13 & 13 & 12 \\
\hline & $\begin{array}{l}\text { In how many products were state tender prices the lowest price compared with } \\
\text { all } 5 \text { proposed benchmark countries incl. SA, } n\end{array}$ & 12 & 12 & 11 \\
\hline & $\begin{array}{l}\text { Products where the SA state tender price was the lowest price compared with all } \\
5 \text { proposed benchmark countries incl. SA, } \%\end{array}$ & 92 & 92 & 92 \\
\hline & Average decrease per country, \% (in products where decrease seen) & & & \\
\hline & Australia & $27(n=11)$ & $35(n=14)$ & $37(n=12)$ \\
\hline & New Zealand & $60(n=6)$ & $53(n=6)$ & $56(n=8)$ \\
\hline & Canada & $2(n=1)$ & $16(n=1)$ & $18(n=1)$ \\
\hline & Spain & $n=0$ & $n=0$ & $30(n=1)$ \\
\hline
\end{tabular}

the proposed basket of comparator countries. Of the 30 countries listed in the summary table, only Spain, Canada, New Zealand and Australia met all criteria (i.e. Pharmaceutical Inspection Co-operation Scheme member, signatory of the Agreement on Trade-Related Aspects of Intellectual Property Rights, use of pharmacoeconomic evaluations, internal and ERP, public spend $>60 \%$ of total health expenditure), and these were the only countries with access to pricing information. Belgium, Hungary, The Netherlands, Poland and Portugal met the criteria with the exception of access to pricing data. ${ }^{[3]}$ The methodology proposed that only Organisation for Economic Cooperation and Development (OECD) countries should be evaluated for inclusion in the basket, one of the reasons being that the OECD would facilitate sharing of information and policy experiences. ${ }^{[3]}$ The lack of accessible and transparent pricing data is an obvious limiting factor. Although BRICS countries were not evaluated for inclusion in the proposed basket of comparator countries, ${ }^{[3]}$ the aim of including them as a separate assessment was to compare pricing in leading emerging markets where the aim of co-operation among the countries is non-competitive, sustainable, equitable and mutually beneficial development. ${ }^{[8]}$ This analysis was limited by the availability of regulated medicine pricing information in India and China. Information for current and historical Brazilian medicine pricing was freely and clearly accessible online and could be translated from Portuguese to English using Google Translate. Similarly, Russian online medicine pricing information also required the use of Google Translate. However, the added complication of a different alphabet made this translation less intuitive, and the identification of appropriate comparator pricing information more tedious, than with the Brazilian comparison. Among the three BRICS countries included in the analysis, Russian pricing was most frequently the lowest. Although the use of Russia as a comparator country for SA may appear favourable on the basis of this analysis, results should be used with caution as attempts to verify pricing information with the Russian State Register of Medicines were not successful. A concern is that the pricing information may be out of date and not a true reflection of the actual current ex-manufacturer pricing in Russia.

SA state tender pricing information was not available for all proposed comparator products, but where it was, it had the lowest price in $92 \%$ of products $(n=38)$. The difference observed between SA private sector ex-manufacturer medicine pricing and SA state sector pricing is driven by volume-based pricing negotiations in the form of state tenders. ${ }^{[9]}$ This assessment, although limited by sample size, should prompt discussion around the possibility that ERP in isolation 


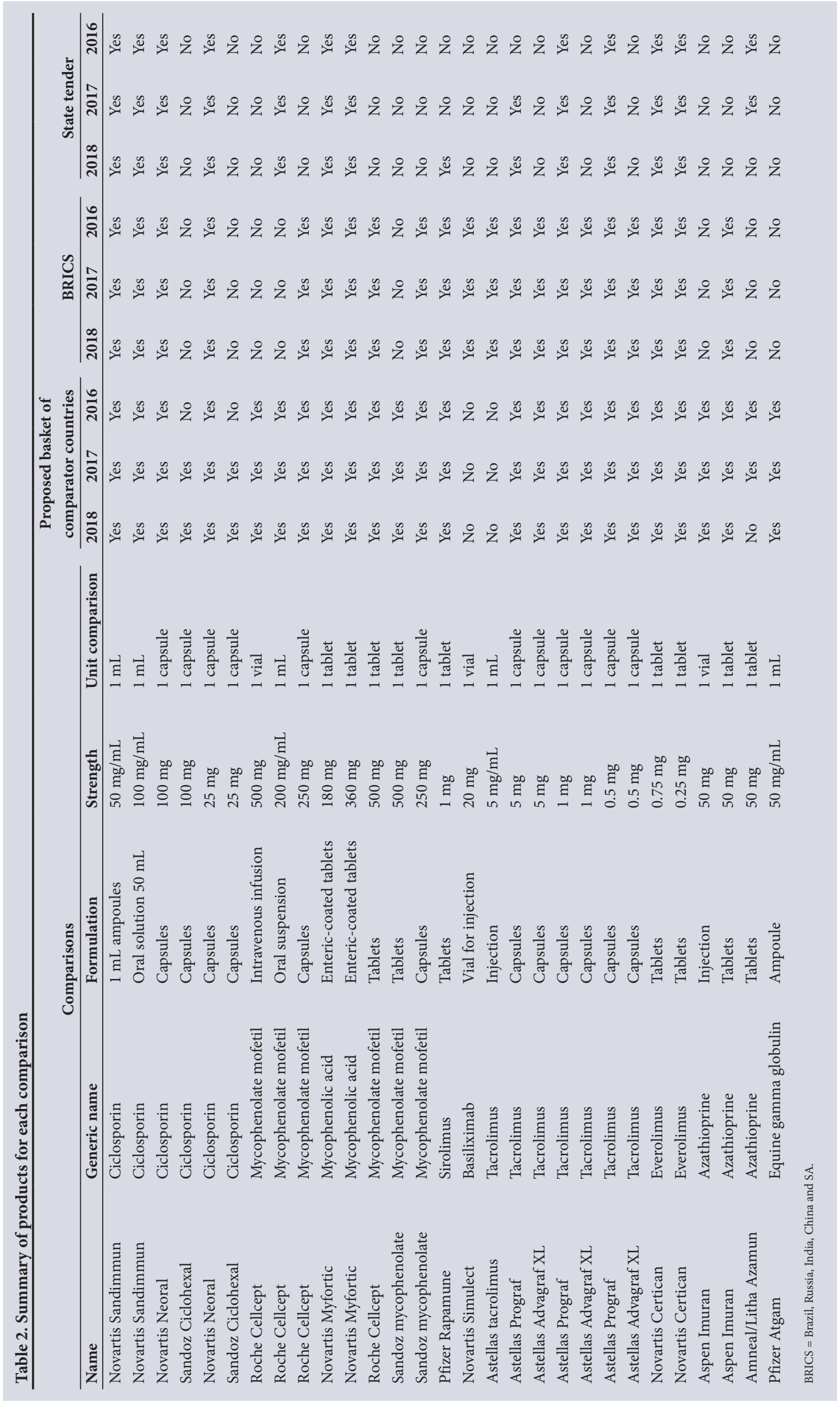


may not generate as favourable medicine pricing as would either volume-based pricing or a combination of the two policies.

Although limited by small sample size and ATC, this analysis has shown that IBM using Australia, New Zealand, Canada and Spain would lower the price of the majority of medicines in this immunosuppressant analysis. It is important to explore why these comparator countries may be generating more favourable medicine pricing than the private sector in SA. Spain, Australia and New Zealand all include a form of internal reference pricing in their national reimbursement policies, and although Canada does not directly regulate off-patent originator and generic pricing, ${ }^{[3]}$ outpatient prescriptions are reimbursed by private insurers who may decide to employ a form of internal reference pricing. Although the use of generic reference pricing of immunosuppressant medicines in transplant recipients is a complex issue, and where implemented may be done with tight controls to avoid switching among products, ${ }^{[19]}$ the use of internal reference pricing by comparator countries does once again highlight the importance of a multidimensional approach to the pricing of medicines in general.

Noted challenges of the observational analysis included access and availability of current and historical pricing data, comprehension of the data available and their applicability within the context of the specific country, and the matching of products for comparison. The medicine pricing information from a comparator country may be meaningless if it is not used with an understanding of the pricing and reimbursement policies, taxation structures and healthcare funding employed in that specific country. In addition, a medicine's price has a specific local history that affects pricing and includes patent expiry timing and the subsequent launch of competitor generics on the market. Medicine prices may be compared across countries at a specific point in time when on- and off-patent market factors may differ. Similarly, the emergence of negotiated confidential discounts and pricing for patient access schemes may affect the transparency of the published medicine pricing and its use in an ERP comparison. The Gazette methodology explicitly details how products should be grouped for comparison; ${ }^{[2-5]}$ however, the reality of the application of this methodology is a challenge and often requires further investigation and occasionally a degree of assumption. For example, a product may match on most factors including trade name, manufacturer and strength, but the publicly available medicine pricing database of one country may list the formulation as a tablet and another country may list it as a filmcoated tablet. Furthermore, the complex nature of the pharmaceutical industry, involving mergers, local marketing or distribution licences, may also complicate confirmation of the same manufacturer source.

The main limitation of this observational analysis is the small sample size and restriction to one therapeutic medicine group, immunosuppressants for organ transplant rejection. The analysis did not attempt to ascertain whether the local registered price of the medicine was already subject to the proposed benchmarking methodology and whether this may have contributed to the reason why SA had the lowest price for certain products. Although applicants may already comply, it must be noted that the benchmarking methodology remains in proposal form and has yet to be formally implemented. This factor may complicate future analyses assessing the impact that formal implementation has on local drug prices.

Since the commencement of this observational analysis, the Euripid Collaboration and the EU Health Programme have published 12 guiding principles for ERP. In July 2018 they published these 12 principles in a guidance document with the aim of 'coordinating approach of national authorities regarding the use of ERP to avoid/ mitigate negative impact for patient access to medicines. ${ }^{[20]}$ Although this document has been developed in a European context, the principles should be considered by any country considering or revising an international benchmarking policy.

\section{Conclusions}

ERP is an internationally applied pricing policy used to regulate the price of medicines and should be formally implemented locally. It should not be used in isolation from other medicine pricing and reimbursement policies. ${ }^{[20]}$ As can be seen in this analysis, both the use of ERP and comparison with the price derived from volumebased pricing in the form of state tenders have the potential to lower the local cost of medicine in the private sector. Even with a shift to a National Health Insurance system, IBM may provide a valuable component within the broader framework of medicine price regulation. Most countries, even those with social health insurance systems, apply a combination of regulatory tools. ${ }^{[3]}$ Denmark, Spain, Canada and France are examples of countries that have used a combination including, but not limited to, pharmacoeconomic guidelines and IBM. ${ }^{[3]}$

High-quality evidence on the long-term effects of pricing policies is limited. Where evidence on the impact of ERP is available, it is limited to country or European experience or an isolated medicine class comparison, which limits the external validity of the observations.

Conducting an ERP analysis, even of one product, consumes time and resources. However, as shown in this small analysis, it may prove to reduce a current or proposed medicine price. It may also provide an opportunity for reflection on how comparator countries are approaching medicine pricing and provide insights for constant local improvement and dynamic medicine pricing policies.

Published medicine pricing information should be updated at regular intervals, clearly stipulate the points at which the medicine price is regulated within the local context, and clarify the applicable taxes that are included or would be added to the published medicine price. Resources should clearly state to which sector the published medicine pricing information applies. This case study is in favour of the proposed benchmarking basket, but as more countries begin to publish medicine pricing information online, the SA basket should be regularly reviewed in order to potentially expand the list of included reference countries.

The common key health focus area of medicine access and the connection among the BRICS countries may facilitate information sharing. The comparison with Russian list prices was favourable, but without formal validation of the prices it is not recommended for inclusion in the basket. Brazil's pricing was often higher than SA's in the analysis, but there were examples where it was lower. A broader analysis across medicine classes should be conducted to further assess how pricing compares between SA and Brazil.

Collaboration between countries to share pricing resources and enhance the benefit derived from ERP methodologies and other pricing policies should be promoted to facilitate improved access to medicine.

Declaration. This research formed part of K-LC's master's dissertation. Acknowledgements. The authors are grateful for the assistance received from colleagues in countries abroad who provided clarity on medicine prices for their respective countries.

Author contributions. FS and K-LC conceptualised the research; K-LC conducted the research; FS validated the data; FS and K-LC contributed to the writing of the article.

Funding. None. 
Conflicts of interest. FS is chair of the National Medicines Pricing Committee.

1. South Africa. Council for Medical Schemes. CMS Annual Report 2017/2018. Annexures 2017/2018. https://www.medicalschemes.com/files/Annual\%20Reports/Annexures_interact.pdf (accessed 21 September 2018)

2. South Africa. Medicines and Related Substances Act, 1965 (Act No. 101 of 1965). Regulations relating to a transparent pricing system for medicines and scheduled substances. Government Gazette No. 28214, 11 November 2005. Published under Government Notice R1102. https://www.gov.za/sites/ default/files/gcis_document/201409/282140.pdf (accessed 21 September 2018).

3. South Africa. Medicines and Related Substances Act, 1965. Regulations relating to a transparent pricing system for medicines and scheduled substances: (Methodology for international benchmarking of prices of medicines and scheduled substances in South Africa). Government Gazette No. 33878, 17 December 2010. Published under Government Notice R1211. https://www.gov.za/sites/default/ files/gcis_document/201409/338781211.pdf (accessed 21 September 2018).

4. South Africa. Medicines and Related Substances Act, 1965. Regulations relating to a transparent pricing system for medicines and scheduled substances: Methodology for international benchmarking pricing system for medicines and scheduled substances: Methodology for international benchmarking
of the prices of medicines and scheduled substances in South Africa. Government Gazette No. 29443, 1 December 2006. Published under Government Notice R1211. https://www.gov.za/sites/default/files/ 1 December 2006. Published under Government Notice R1211. ht
gcis_document/201409/29443b.pdf (accessed 21 September 2018).

gcis_document/201409/29443b.pdf (accessed 21 September 2018).
5. South Africa. Medicines and Related Substances Act (Act No. 101 of 1965). Regulations relating to a transparent pricing system for medicines and scheduled substances: (Benchmark methodology). Government Gazette No. 37625, 12 May 2014. Published under Government Notice R354. https:// www.gov.za/sites/default/files/gcis_document/201409/37625rg10189gon354.pdf (accessed 21 September 2018)

6. Srivastava D, McGuire A. Analysis of prices paid by low-income countries - how price sensitive is government demand for medicines? BMC Public Health 2014;14(1):767. https://doi.org/10.1186/14712458-14-767

7. Kwabena Tetteh E. Providing affordable essential medicines to African households: The missing policies and institutions for price containment. Soc Sci Med 2008;66(3):569-581. https://doi org/10.1016/..socscimed.2007.10.003
8. BRICS 2018. South Africa: 2018. http://www.brics2018.org.za/ (accessed 30 September 2018).

9. National Department of Health, South Africa. Tenders. 2018. http://www.health.gov.za/index php/2015-05-15-12-36-34 (accessed 30 September 2018).

10. Australian Government: Department of Health. Pharmaceutical Benefit Scheme. $2018 \mathrm{http}: / /$ www.pbs. . Australian Government: Department of Health. Pharmaceutical Benefit Scheme. 2018
govau/info/industry/pricing/ex-manufacturer-price (accessed 30 September 2018).

11. Alberta Blue Cross, Canada. 2018. https://www.ab.bluecross.ca/dbl/publications.html (accessed 30 September 2018

12. PHARMAC, New Zealand. 2018. https://www.pharmac.govt.nz/tools-resources/pharmaceuticalschedule/ (accessed 30 September 2018).

13. Spanish Ministry of Health. 2018. https://www.mscbs.gob.es/en/profesionales/nomenclator.do (accessed 30 September 2018).

4. National Pharmaceutical Pricing Authority, India. 2018. http://nppaimis.nic.in/nppaprice/ newmedicinepricesearch.aspx (accessed 30 September 2018).

15. Tamil Nadu Medical Services Corporation Limited, India. 2018, http://www.tnmsc.com/tnmsc/new/ index.php (accessed 30 September 2018)

16. Fang Y. Pharmaceutical pricing policies in China. In: Babar ZUD, ed. Pharmaceutical Prices in the 21st Century. Adis, Cham, 2015:43-58. https://doi.org/10.1007/978-3-319-12169-7_3 (accessed 21 September 2018)

17. China Food and Drug Administration Database. 2018. http://appl.sfda.gov.cn (accessed 30 September 2018).

18. South African Reserve Bank. 2018. https://www.resbank.co.za/Research/Rates/Pages/ South African Reserve Bank. 2018. https://www.resbank.co.za/k
SelectedHistoricalExchangeAndInterestRates.aspx (accessed 30 September 2018).

19. Allard J, Fortin MC. Is it ethical to prescribe generic immunosuppressive drugs to renal transplan patients? Can J Kidney Health Dis 2014;1(1):23.

20. Habl C, Schneider P, Németh G, Šebesta R. Euripid Guidance Document on External Reference Pricing (ERP). European Commission, Consumer, Health and Food Executive Agency (Chafea), Brussels. https://jasmin.goeg.at/432/ (accessed 30 September 2018).

Accepted 29 April 2019 